\title{
The Development of Centering Perforation Machine for Ingot
}

\author{
Xing $\mathrm{Gu}^{1, \text { a }}$, Ning Lin ${ }^{1, \mathrm{~b}}$, Weijun Wang ${ }^{1, \mathrm{c}^{*}}, \mathrm{Qx} \operatorname{Lin}^{1, \mathrm{~d}}$, Xiang Gu $\mathrm{u}^{2, \mathrm{e}}$ \\ ${ }^{1}$ Guangzhou Institute of Advanced Technology, Chinese Academy of Sciences, Guangzhou, China \\ ${ }^{2}$ Anji North Automobile Inspection and Test Co.,LTD, Huzhou, China \\ ${ }^{3}$ List all distinct addresses in the same way \\ aguxing066@outlook.com, bInsin@126.com, cwj.wang@giat.ac.cn, 'qx.lin@giat.ac.cn , \\ 'guxiang120@163.com
}

Keywords: seamless pipe, perforation, centering

Abstract. This paper introduces the currently manufacture process of seamless pipe and the main factors that reduced seamless pip quality and quantity during production. Developing a machine that can automatically detect center point of raw ingot and punch oriented hole besides, it's controlled by a remote control system will do a great contribute to the manufacturing quality and efficiency. Introduces the mechanical-structural of Centering Perforation Machine and analysis the general work process of this machine. Accomplishes the industrial field monitoring of production process based on WINCC and Siemens PLC S7-300.

\section{Introduction}

Seamless steel pipe play an important role in the military, construction and other business. The uniformity of steel pipe thickness is the criteria of the quality that must meet national standards. Currently, seamless tube's manufacturing process mainly include three steps. Firstly manually measure the central position and draw a mark point on the end plane of raw ingot (refer to Fig.1), then perforate a hole by using heated electrode according to the marked position and this hole will be a guidance for next punching process (refer to Fig2). Finally, a punching machine will be used to perforate the whole ingot (refer to Fig.3). Because of the low efficiency and locating precision in perforation process, the quality and production of seamless pipe is decreased. Besides, poor working conditions (high temperature, noisy etc.) do great harm to workers.

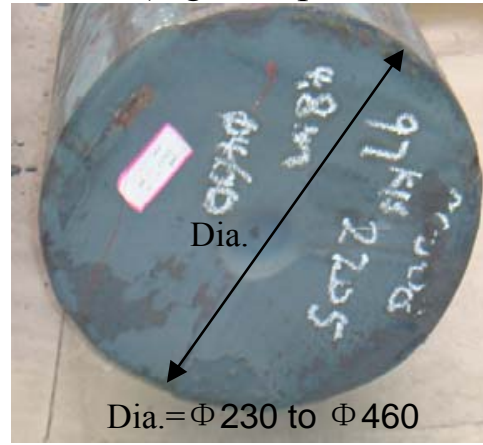

Fig. 1 Raw ingot

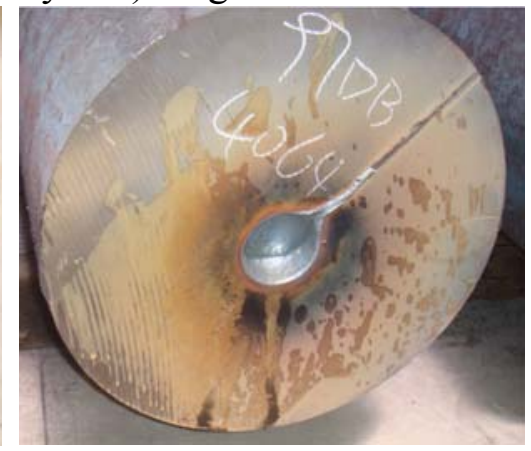

Fig.2 hot-melt an oriented hole

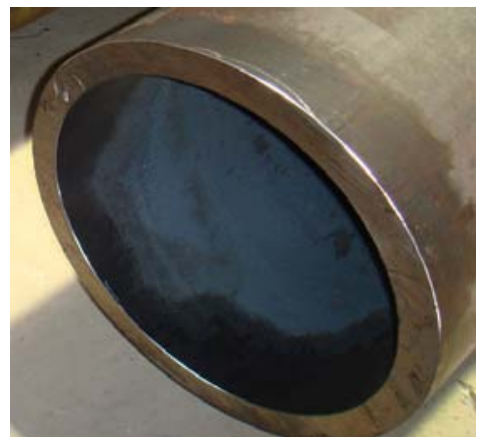

Fig.3 Final product( after forging)

Because of these disadvantages as mentioned before, we developed the Centering Perforation Machine taking place of human to finish the perforation process and the machine should satisfy the following functions:

1) Automatically detect the center coordinate on the end plane of ingot.

2) Adjust the electrode center alignment to ingot center and perforate a guide hole.

3) Remote monitoring and control available.

4) The diameter of perforated hole should be adjustable based on different ingot size.

\section{Specification}

1) Locating accuracy for center hole: $\pm \Phi 1 \mathrm{~mm}$.

2) Ingot size range from $\Phi 230$ to $\Phi 460 \mathrm{~mm}$

3) Cycling time $: 3$ minutes 
4) Maximum central hole : $\Phi 80 \mathrm{~mm} \times 120 \mathrm{~mm}($ depth)

5) Ambient temperature: $-10^{\circ} \mathrm{C}$ to $+70^{\circ}$

Centering Perforation Machine is composed of Industry Computer WINCC configuration software and perforation mechanism. The application of PLC and WINCC realized remote control and real-time monitoring improved production efficiency perforation quality.

\section{Composition of Automatic Centering Perforation Machine Structure}

The composition of Centering Perforation Machine for seamless pipe manufacturing is as shown in Fig3, Which mainly include the following three parts: 1) the circle center detection component on the ingot section. A pair of laser ranging sensor used to scan the cylinder ingot cross section outline along with linear guide direction $X$ (set as axis X1, X2 for each sensor). 2) Electrode center adjustment component. Servomotor $Y$ and servomotor $X$ used to drive the electrode translating along with $X$ and $\mathrm{Y}$ direction, then align point $\mathrm{O}_{1}$ on electrode to point $\mathrm{O}_{0}$ on the center of ingot section. 3) Laser sensor protective component. 4) Hole slash component, it makes oriented hole (refer in Fig.2) size can be adjusted according to different ingot diameter.

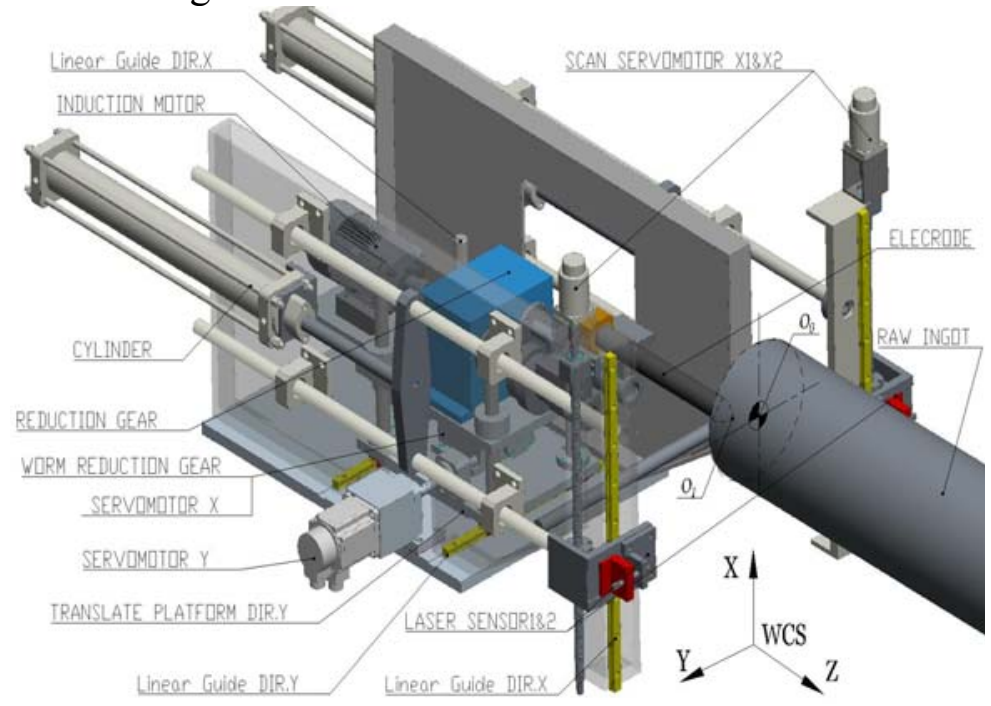

Fig.4 Composition of Automatic Centering Perforation Machine

\subsection{Circle center detection component on the ingot section}

Circle center detection component is as shown in Fig.5.The servomotor X1 and X2 will drive the laser sensor1 and sensor2 scanning from top to bottom along with the linear guide trail to detect the ingot section outline. The two laser sensors will detect the distance from the sensor to ingot surface which are named as Di1 and Di2 as shown in Fig.5. For every scanning process, the sensors will take 60 sets data at a $0.2 \mathrm{~s}$ sampling time, then transfer the 60 sets distances data to PLC system. PLC system will calculate the coordinate of every surface point $\mathrm{P}_{\mathrm{i} 1}\left(\mathrm{X}_{\mathrm{i} 1}, \mathrm{Y}_{\mathrm{i} 1}\right), \mathrm{P}_{\mathrm{i} 2}\left(\mathrm{X}_{\mathrm{i} 2}, \mathrm{Y}_{\mathrm{i} 2}\right)$ and get the coordinate of raw ingot section center point $\mathrm{O}_{0}$ (refer to Fig.4) with an fitting algorithm used.

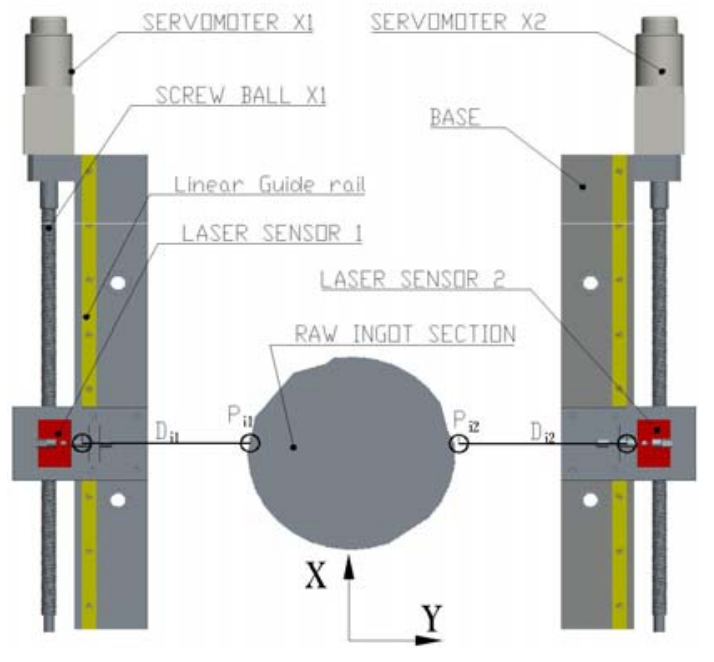

Fig 5. Circle center detection 


\subsection{Electrode center adjustment component}

As shown in Fig.6, the electrode center adjustment component contain 2 degrees of freedom. Servomotor Y drive platform1 translating on Y direction. Platform2, induction motor and reduction gear are all mounted on platform1. Servomotor X connect with worm reduction gear that can drive lifting shaft translating along with linear guide on $\mathrm{X}$ direction together with platform2. With this mechanism used, the electrode can translate along with $\mathrm{X}$ and $\mathrm{Y}$ direction to align point $\mathrm{O}_{1}$ on electrode center to point $\mathrm{O}_{0}$ detected on the center of ingot section.

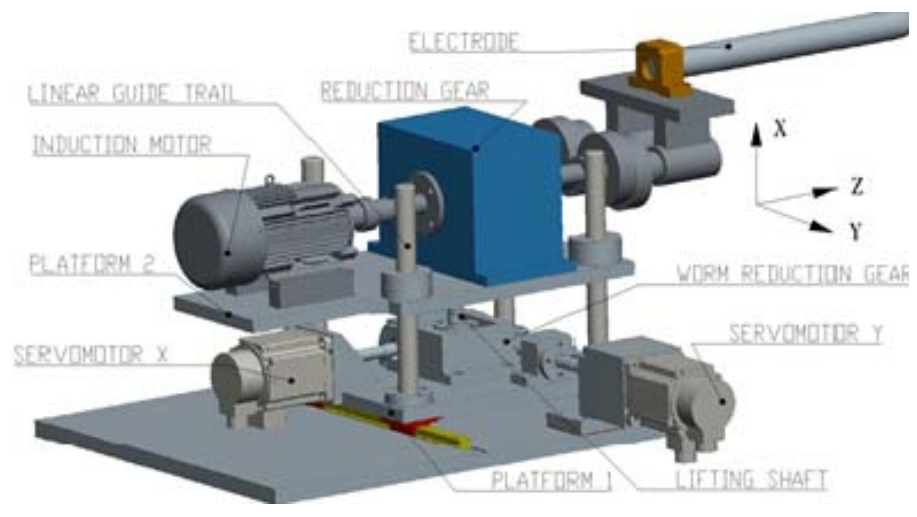

Fig.6 Electrode center adjustment component

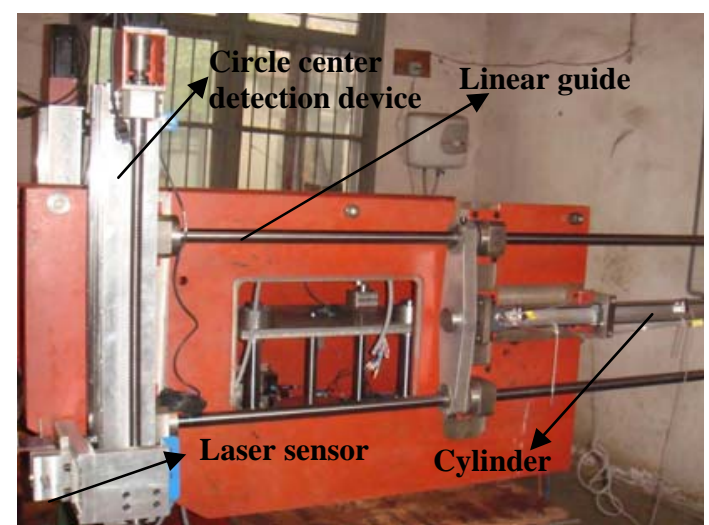

Fig.7 Laser sensor protective component

\subsection{Laser sensor protective component}

When laser sensors scan the ingot section outline, cylinder will push the detection device to working position as shown in Fig.7. Until the detection process finished, cylinder will pull the detection device back to heat insulation case (disassembled in Fig.7) for avoiding of the electric arc and heat during manufacturing.

\subsection{Hole slash component}

The diameter size of oriented hole in Fig.2 is different according to size of seamless pipe but the diameter of carbon electrode is $\Phi 45 \mathrm{~mm}$ that is unchangeable. The following mechanism in Fig. 8 is designed to increase hole size to $\Phi 80$. The reduction gear has two output shafts, each shaft connect to linkage via tuner screw which were axial fixed. As shown in Fig. $9 \mathrm{O}_{0}$ is the center of output shaft and $\mathrm{O}_{1}$ is the center of reduction gear output shaft. By wrenching tuner screw, the nut will translate along with tuner screw then eccentric value $\delta$ can be adjusted. So the structure is a four-link structure, the output shaft and reduction gear output shaft constitute of crank and the electrode center is one point on linkage which will do a rotational motion as radius $\delta$.

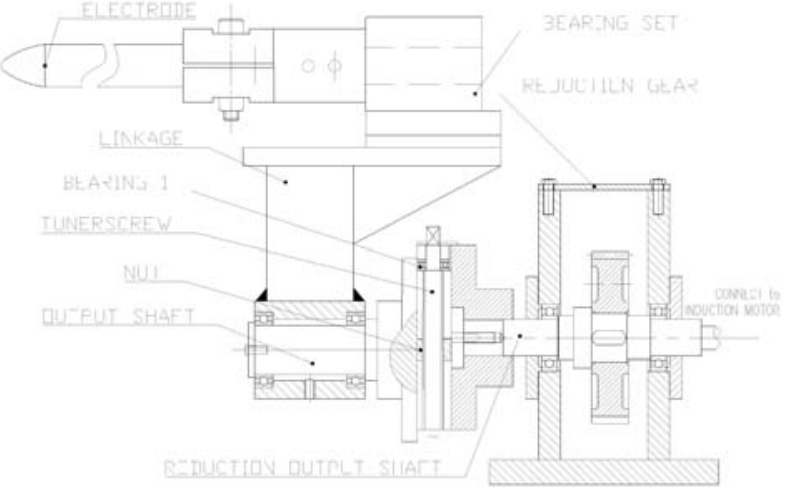

Fig.8 hole slash mechanism(a)

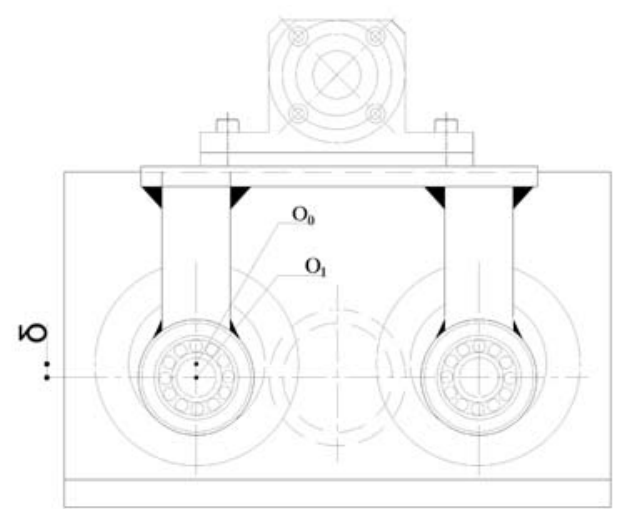

Fig.9 hole slash mechanism(b)

\section{Composition of Automatic Centering Perforation Machine Control}

The layout of control system is as shown in Fig.10. SIEMENS S7-300 PLC is preferred as lower computer hardware to collect digital and analog signal in industry field. Industry computer installed 
with WINCC software and CP5611 communication card will communicate PLC system through PROFIBUS-DP.

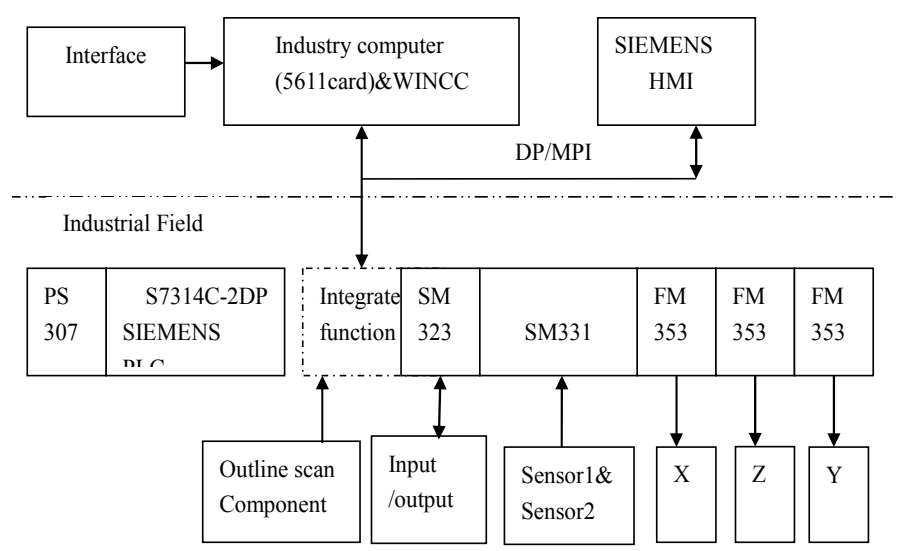

Fig.10 Composition of Control System

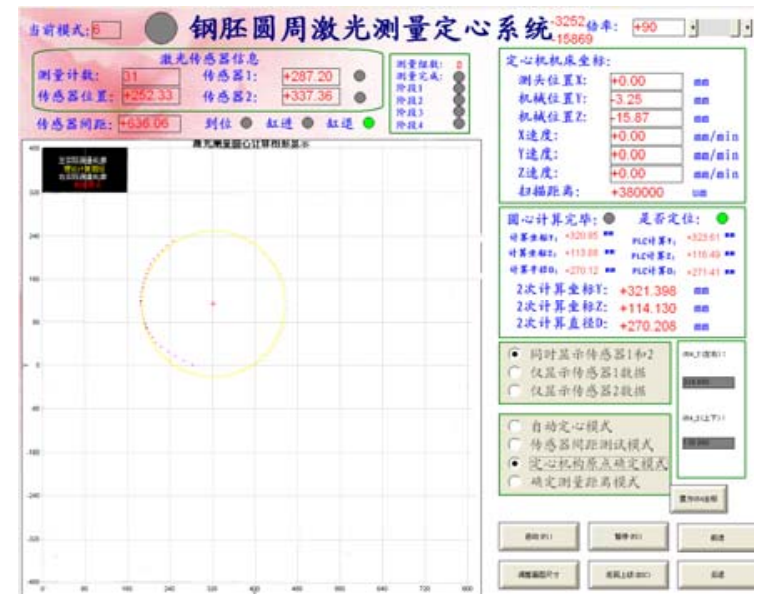

Fig.11 Automatic run interface

Host computer mainly used for remote monitoring of punching process. Operators can use the human-machine interface on industry computer to remote operate centering machine, away from dangerous environment. As shown in Fig. 11 the interface of WINCC under automatic punching mode. The yellow circle is the fitting result based on scanned data which colored red in Fig.11

\section{Summary}

Paper introduced the mechanical structure of Centering Perforation Machine, the principle of the control system and the significance of the equipment in the process of research and development in seamless steel pipe production. Through the practical application shows that the equipment greatly improve the accuracy of the centering punching and drilling efficiency, improved labor productivity and the quality of drilling.

\section{References}

[1] SIEMENS.FM353 Stepper Drive Positioning Module.10.2000 Edition.2003.Reference to a book:

[2] Sheng Qiang,Gao,X.Z,Xianyi Zhuang.PLC-based control systems for industrial production of fuel alcohol.Industrial Technology.IEEE,Volume 2,Dec.2002.Page(s):827 832

[3] Xing Gu , Weijun Wang, Ning Lin, Dongik Shin, The Finite Element Analysis of Batching Machine Spindle Based on ANSYS, ICMEMSCE2013, Beijing,China ,pp 216-219

[4] Li Yong-bo ,Yang Liu, Fang Shao-xi. Control System of Billet Centering Perforation. Computer and Automation Engineering (ICCAE), 2010 The 2nd International Conference on.IEEE,26-28 Feb. 2010.Page(s): 288 - 291 